\title{
Targeting HMGB1 inhibits bladder cancer cells bioactivity by lentivirus- mediated RNA interference
}

\author{
W. WANG ${ }^{1}$, H. ZHU ${ }^{3}$, H. ZHANG ${ }^{2}$, L. ZHANG ${ }^{2}$, Q. DING ${ }^{1,2}$, H. JIANG ${ }^{1,2, *}$ \\ ${ }^{1}$ Institute of Urology, Huashan Hospital, Fudan University; ${ }^{2}$ Department of Urology, Huashan Hospital, Fudan University; ${ }^{3}$ Department of ICU, \\ Huashan Hospital, Fudan University
}

*Correspondence: drjianghaowen@126.com

Received December 17, 2013 / Accepted March 13, 2014

\begin{abstract}
High mobility group box 1(HMGB1) has been reported to be associate with tumor clinical stage and pathological grade in bladder cancer (BC). In this study, we investigated the underlying mechanism through lentivirus-mediated HMGB1 knockdown. HMGB1 was strongly inhibited in BC cells stably transfected with shRNA against HMGB1. MTT and colony formation assays demonstrated that the down-regulation of HMGB1 attenuated the growth of BC cells in vitro. The HMGB1 knockdown (KD) group displayed an increased proportion of cells in the G0/G1 phase and higher apoptosis rates of BC cells comparing with the control (CON) group. The transwell assay revealed that the KD group cells had much lower invasive activity. To assess the influence of HMGB1 inhibition on tumorigenicity in BC cells, shRNA-HMGB1 lentivirus were injected into the tumors of xenograft models and the results showed that the tumorigenesis in mice were significantly suppressed by shRNA-HMGB1 lentivirus. Furthermore, the expression level of VEGF-C in KD group was significantly decreased comparing with the CON group. The NF- $\kappa B$ inhibitor PDTC reduced the expression of VEGF-C, while HMGB1, as a NF- $\kappa B$ agonist, enhanced the VEGF-C expression. In conclusion, our results suggested that lentiviruses delivering shRNA against HMGB1 may be a promising tool for BC therapy.
\end{abstract}

Key words: HMGB1, bladder cancer, RNA interference, proliferation

Bladder cancer $(\mathrm{BC})$ is the most common genitourinary malignancy in the world the fourth most common type of cancer in men and the eighth most common in women in the United States and the 10th most common cancer in China $[1,2]$. A recent study showed that $39-47 \%$ persistent nonmuscle-invasive $\mathrm{BC}$ patients would need a re-resection therapy [3]. About 20\% re-resection T1 tumors progressed to invasive $\mathrm{BC}$, and this is associated with a high rate of early metastases and poor long-term survival [4]. It was important to predict the invasive behavior of $\mathrm{BC}$ in clinical work, and the novel biomarkers should provide important predictive and prognostic information and be incorporated in clinical decision-making $[5,6]$.

High mobility group box 1 (HMGB1) protein is a ubiquitous, abundant nuclear protein [7]. It had a tripartite domain organization, consisting of two DNA-binding domains, the HMG-boxes $\mathrm{A}$ and $\mathrm{B}$, and acidic $\mathrm{C}$-terminal tails of variable length [7]. HMGB1 had various biological functions within the nucleus, such as binding to DNA without sequence specificity, regulating transcription, replication, DNA repair and recombination[8]. HMGB1 could be passively released into the extracellular milieu from necrotic cells or actively secreted by various immune cells via a non-conventional specialized pathway[9]. In 1999, Wang et al. first reported that HMGB1 played an important role in mediating experimental sepsis [10]. HMGB1 could be bind to the receptor for advanced glycation end products (RAGE), and Toll-like receptors (TLR2 $\& 4$ ) to trigger the inflammatory pathway [11].

Overexpression of HMGB1 had been observed in several human cancers, including hepatocellular carcinoma [12], skin squamous cell carcinoma [13], prostate carcinoma [14], gastrointestinal carcinoma [15], breast carcinoma [16] and bladder cancer (BC) [17]. Our early study also showed that HMGB1 was correlated with tumor clinical stage and pathological grade in $\mathrm{BC}[18]$. It is also correlated with vascular endothelial growth factor (VEGF) expression and microvessel density (MVD) counts, suggesting HMGB1 might act as a key regulator in progression and angiogenesis of $\mathrm{BC}$ [18].

To further elucidate the role of HMGB1 in BC, we used lentivirus-delivered shRNA to suppress the expression of HMGB1. 
Using this model system, we investigated the influence of HMGB1 shRNA on the proliferation, NF- $\mathrm{kB} / \mathrm{p} 65$ and VEGF-C expression of bladder cancer cells and examined the consequent antitumor potential of HMGB1 shRNA in vivo and in vitro.

\section{Materials and methods}

Cells lines and cell culture. The 293T human renal epithelial cell, 5637 and T24 human urinary BC cell lines were purchased from American Type Culture Collection and maintained at $37^{\circ} \mathrm{C}$ and $5 \% \mathrm{CO}_{2}$. The $293 \mathrm{~T}$ cell lines were cultured in DMEM (Invitrogen, Carlsbad, CA) supplemented with 10\% fetal bovine serum (FBS, Invitrogen). The 5637 and T24 BC cell lines were maintained in ATCC-formulated RPMI-1640 (Invitrogen) supplemented with 10\% FBS.

Lentivirus production and cell infection. The shRNA sequence ( 5'-GAAGAAGATGAAGATGAAGAATTCAAGAGATT

CTTCATCTTCATCTTCTTCTTTTTTACGCGT-3') targeting human HMGB1 gene was selected from three potential sequences (Table S1 and Fig S1). Pairs of complementary oligonucleotides for these sequences were synthesized (Genechem, Shanghai, China), annealed, and ligated into the pHBLV-U6-Puro lentiviral RNAi vector (Hanbio, Shanghai, China) linearized by BamH I and EcoR I. The recombinant lentivirus with HMGB1-shRNA was produced by co-transfection of 293T cells with plasmids PSPAX2 and PMD2G with LipoFiter (Hanbio, Shanghai, China). Lentiviruses-containing supernatant were harvested $48 \mathrm{~h}$ after transfection and filtered through $0.22-\mu \mathrm{m}$ cellulose acetate filters (Millipore, USA). Recombinant lentiviruses were concentrated by ultracentrifugation $(2 \mathrm{~h}$ at $50,000 \times \mathrm{g})$. These particles are hereafter referred to as Lv-shHMGB1 (specific interference construct for HMGB1), and the empty lentiviruses without HMGB1-shRNA were used as negative control (Lv-NC).

To establish stable HMGB1-konckdown cell lines, 5637 and T24 BC cells ( $30 \%$ confluent) were transducted with LvshHMGB1 at an MOI of approximately 10 in the presence of $5 \mu \mathrm{g} / \mathrm{ml}$ polybrene. After 24 hours, culture medium was removed and fresh medium was added to the cells. 72 hours after transduction, puromycin was added to medium at the concentration of $5 \mathrm{mg} / \mathrm{ml}$ for stable cell line selection. After antibiotic selection for 3 weeks, stable HMGB1-konckdown cells were obtained. BC cells were then divided into the following three experimental groups: the CON group (non-infected cells), the NC group (Lv-NC-infected cells), and the KD group (HMGB1-konckdown cells).

Real-time PCR and western blotting analysis. Total RNA was extracted from cells using Trizol reagent (Invitrogen) and reverse transcribed using M-MLV Reverse Transcriptase (Promega, Madison, WI) following the manufacturer's protocol. Quantitative real-time PCR reactions were prepared in a volume of $25 \mu \mathrm{l}$ containing $0.1 \mu \mathrm{M}$ primers, $10 \mu \mathrm{l} 2 \times \mathrm{SYBR}$ Premix Ex Taq (Takara, Osaka, Japan), and 20-100 ng cDNA sample and assayed using a TP800 system (Takara). The primers used were as follows: for HMGB1, 5'-ATATGGCAAAAGCGGACAAG-3' and 5'- GCAACATCACCAATGGACAG-3; for NF-кB/p65: 5'-AAAGACTGCCGGGATGGCTTCTAT-3' and 5'TTCCAGGTCCCGCTTCTTTACACA-3'; for $\beta$-actin, 5'-ctccatcctggcctcgctgt- $3^{\prime}$ and 5'-gctgtcaccttcaccgttcc-3'. The amplification program consisted of $95^{\circ} \mathrm{C}$ for $15 \mathrm{~s}$ and 45 cycles of denaturation at $95^{\circ} \mathrm{C}$ for $5 \mathrm{~s}$, annealing and extension at $60^{\circ} \mathrm{C}$ for $30 \mathrm{~s}$. The relative amount of HMGB1 mRNA was calculated by the $2^{-\Delta \Delta \mathrm{Ct}}$ method using the $\beta$-actin mRNA level for normalization[19]. All experiments were repeated at least three times.

To detect the protein level, cells were lysed using Nuclear Extract Kit (Active Motif, Carlsbad, CA, USA) according to the manufacturer's instructions. The lysates were ultracentrifuged at $14,000 \times \mathrm{g}$ for $30 \mathrm{~s}$ at $4{ }^{\circ} \mathrm{C}$, and the supernatant (cytoplasmic extract) was collected to evaluate contents of HMGB1 and VEGF-C. The pelleted nuclei were resuspended in Complete Lysis Buffer. After $30 \mathrm{~min}$ at $4{ }^{\circ} \mathrm{C}$, lysates were centrifuged at $14,000 \times \mathrm{g}$ for $10 \mathrm{~min}$, the supernatant (nuclear extract) was collected to evaluate the content of NF-kB/p65. Endogenous glyceraldehyde 3-phosphate dehydrogenase (GAPDH) or TATA binding protein (TBP) was used as an internal standard for cytoplasmic protein or nuclear protein respectively. Protein samples $(30 \mu \mathrm{g} / \mathrm{lane})$ were separated on $12 \%$ SDS-PAGE gels and transferred onto PVDF membranes (Millipore, Bedford, MA). After blocked, the membranes were incubated with rabbit anti-HMGB1 (1:200, Abcam, Cambridge, UK), anti-NF-кB/p65 (1:1000, Abcam), anti-VEGF-C antibody (1:1000, Abcam) and mouse anti-GAPDH (1: 5000, Santa Cruz Biotechnology) and anti-TBP antibody (1: 5000, Abcam) overnight at $4^{\circ} \mathrm{C}$. After washed with Tris-buffered saline/Tween-20 solution, the membranes were incubated with horseradish peroxidase-conjugated goat anti-rabbit IgG (1: 5000, Santa Cruz Biotechnology, Santa Cruz, CA) or goat anti-mouse IgG (1: 5000, Santa Cruz Biotechnology) at room temperature for $1 \mathrm{~h}$. Bands were detected with enhanced chemiluminescence.

Cell proliferation and viability measurement. Cells were trypsinized and resuspended for proliferation and viability measurement. For 3-(4,5-dimethylthiazol-2-yl)-2,5-diphenyltetrazolium bromide (MTT) assay, cells were seeded into 96-well plates $\left(5 \times 10^{3}\right.$ cells per well in $100 \mu$ l culture medium) and incubated at $37^{\circ} \mathrm{C}$. The number of viable cells was measured after 1, 2, 3, 4 and 5 days. At each time point, $10 \mu$ l of $5 \mathrm{mg} / \mathrm{ml} \mathrm{MTT}$ was added into each well, and cells were incubated for $4 \mathrm{~h}$. The medium was then removed, and $100 \mu \mathrm{l}$ dimethyl sulfoxide was added. The absorbance was measured at $570 \mathrm{~nm}$ using a microplate reader (Bio-Rad).

For the cell colony formation assay, cells were seeded into dishs at a concentration of 200 cells per dish and cultured at $37^{\circ} \mathrm{C}$ for 14 days. Medium was replaced every 3-4 days. Cells were washed twice with PBS, fixed with paraformaldehyde, stained with Giemsa (Sigma-Aldrich, MO, USA) for $10 \mathrm{~min}$, and washed with $\mathrm{ddH}_{2} \mathrm{O}$ three times. The plates were photographed with a digital camera. Each experiment was performed in triplicate and repeated three times. 
Cell cycle analysis. Cells were harvested and sequentially washed with cold PBS, fixed in 70\% cold ethanol, centrifuged at $400 \times \mathrm{g}$ for $5 \mathrm{~min}$, and resuspended in PBS. Cells were then filtered through a 400-mesh membrane, stained with propidium iodide (PI) in the dark at $4^{\circ} \mathrm{C}$ for $30 \mathrm{~min}$ and analyzed using flow cytometry (Becton Dickinson). Each experiment was conducted in triplicate.

Cell apoptosis assay. After cells were harvested and resuspended, FITC-Annexin V and propidium iodide (PI) were added following the instruction of annexin V-FITC apoptosis detection kit (B.D. Biosciences Pharmingen, San Jose, CA, USA). Stained cells were then quantified by flow cytometry (Becton Dickinson). Each experiment was conducted in triplicate.

Cell invasion assay. Invasion assays were performed in a six-well transwell chamber (Corning, Cambridge, USA), which contained an $8 \mu \mathrm{m}$ pore size polycarbonate membrane filter and was precoated with $100 \mu \mathrm{g}$ Matrigel (Becton-Dickinson, Bedford, USA). Cells were trypsinized and suspended in a serum-free medium containing $1 \%$ BSA at a concentration of $5 \times 10^{4}$ cells/insert. Medium supplemented with $10 \%$ fetal calf serum was added to the bottom chamber. After re-culturing with $5 \% \mathrm{CO}_{2}$ at $37^{\circ} \mathrm{C}$ for $24 \mathrm{~h}$, the transwell chambers were inverted and stained with hematoxylin. Five fields were randomly selected and the number of trans-membrane cells was counted.

The concentration of VEGF-C measurement. The 5637 $\mathrm{BC}$ cells were treated with $10 \mu \mathrm{M}$ PDTC (NF- $\mathrm{KB}$ inhibitor, Beyotime, China) and cells in KD group were treated with

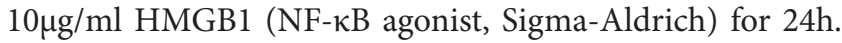
The concentrations of VEGF-C in the supernatant of CON, $\mathrm{NC}, \mathrm{KD}, \mathrm{KD}+\mathrm{PDTC}$ and $\mathrm{CON}+\mathrm{HMGB} 1$ groups were detected using ELISA kit (R\&D, MN, USA) following the manufacturer's instructions.

Animal experiments. Five-week-old male BALB/c mice were purchased from Shanghai Slac Laboratory Animal Co. Ltd (Shanghai, China). $2 \times 10^{7} 5637$ BC cells were suspended in DMEM medium and injected subcutaneously into the right flank of mice. After 10 days, mice with similar size of tumor were divided into three groups (10 mice per group) referred to as the NS (injecting $0.1 \mathrm{ml}$ physiological saline), Lv-NC(injecting $0.1 \mathrm{ml} 1 \times 10^{9} \mathrm{TU} / \mathrm{ml} \mathrm{Lv}-\mathrm{NC}$ ), and Lv-HMGB1(injecting $0.1 \mathrm{ml}$ $1 \times 10^{9} \mathrm{TU} / \mathrm{ml} \mathrm{Lv}$-shHMGB1) groups. Physiological saline or lentivirus particles were injected into the xenograft tumor with above-mentioned dose every $7 \mathrm{~d}$. The tumor diameter was measured, and the volume (product of $0.4 \times$ largest diameter $\times$ smallest diameter $\times$ smallest diameter) was calculated on day 10, 15, 22 and 30. Mice were photographed and humanely killed on day 30 , and the tumors were dissected and weighed.

Statistical analysis. All data were expressed as mean \pm SD. Statistical analysis was performed using SPSS 18.0 (SPSS, Chicago, USA). The statistical correlation of data between groups was analyzed by Student's $t$ test. Statistical significance was accepted at $p<0.05$.

\section{Results}

Downregulation of HMGB1 expression in bladder cancer cells by lentivirus-mediated RNAi. Real-time PCR analysis showed that the mRNA expression of HMGB1 in 5637 and T24 BC cells in the KD group was significantly decreased than in the CON group and the NC group $(p<0.05$, Fig. $1 \mathrm{~A}$ and
A

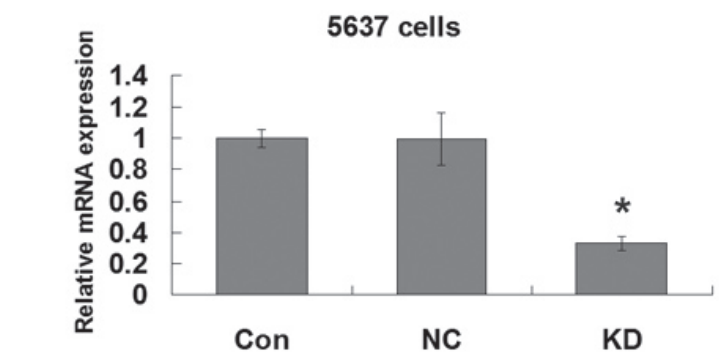

C

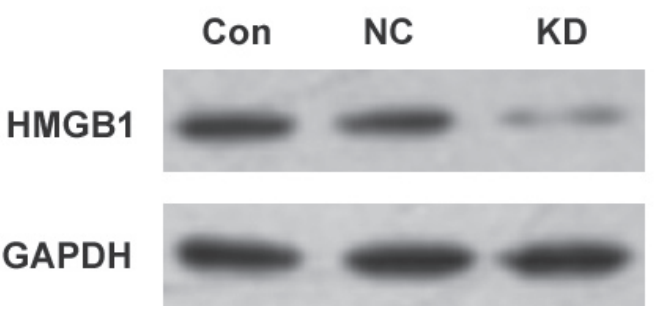

B
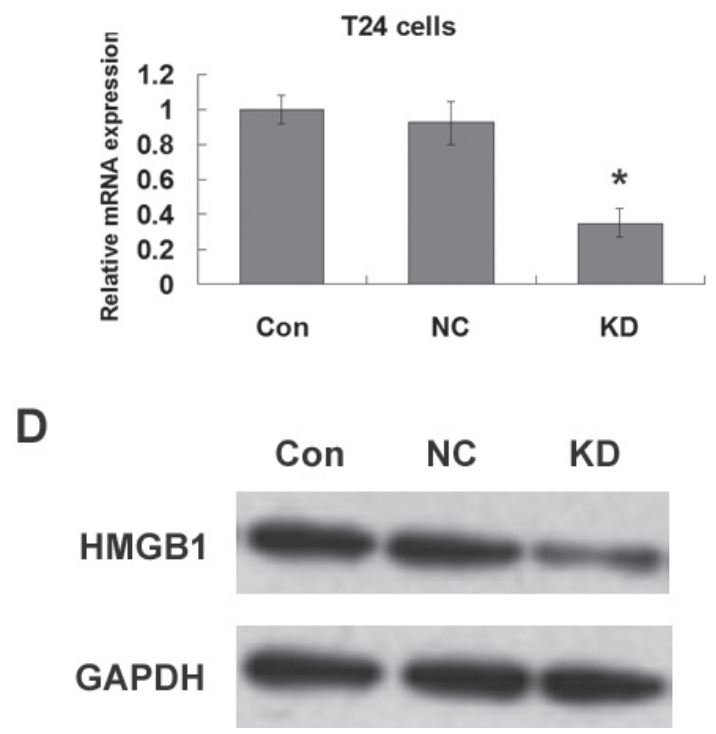

Figure 1. Lv-shHMGB1 mediated RNAi silencing significantly inhibited HMGB1 expression in BC cells. 5637 and T24 BC cells were untreated or infected with Lv-shHMGB1 or Lv-NC, and then the stably transfected cells were selected. (A) Real-time PCR analysis of HMGB1 mRNA expression. ${ }^{\star} p<0.05$, vs CON group. (B) Immunoblot analysis of HMGB1 protein expression. 
B). Immunoblot analysis showed the decreased expression of HMGB1 protein in the KD group (Fig. 1C and D). Thus, the endogenous HMGB1 has been silenced in BC cells transfected stably with shHMGB1.

Knockdown of HMGB1 inhibited the growth and invasive activity of $\mathrm{BC}$ cells in vitro. To investigate whether the downregulation of HMGB1 resulted in suppression of BC cell growth, the proliferation and viability of 5637 and T24 BC cells were assessed by MTT assay, and colony formation assay. MTT assay indicated that the KD group displayed a significant cell proliferation defect compared to the $\mathrm{CON}$ and $\mathrm{NC}$ groups $(p<0.05$, Fig. $2 \mathrm{~A})$. A colony formation assay revealed that the number of colonies was decreased in $\mathrm{KD}$ group compared to the CON and NC group ( $p<0.05$, Fig. $2 \mathrm{~B})$.

To determine whether the downregulation of HMGB1 impacts the cell cycle and apoptosis of $\mathrm{BC}$ cells, all three groups of 5637 and T24 BC cells were subjected to flow cytometry analysis. The $\mathrm{KD}$ group of both $\mathrm{BC}$ cells displayed increased proportions of cells in the G0/G1 phase compared to that of

A 5637 cells

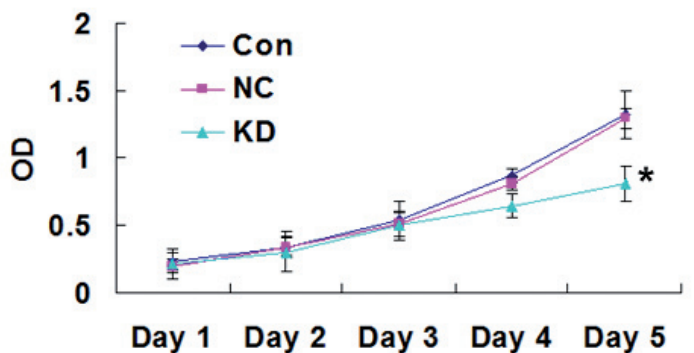

the CON group and the NC group ( $p<0.05$, Fig. $3 \mathrm{~A}$ ) implying the cell cycles were been blocked in G0/G1 phase. The cell apoptosis assay showed that the volume of apoptotic cells in KD group was significantly increased comparing with that in the CON and NC groups ( $p<0.05$, Fig. $3 \mathrm{~B}$ ). These results partly explained how HMGB1 knockdown reduced BC cell proliferation.

The Transwell assay revealed that the KD group transfected with Lv-shHMGB1 had much lower invasive activity than the CON and NC group ( $p<0.05$, Fig. 3 C). Since there was no obvious differences in the number of cells in culture for $24 \mathrm{~h}$ (Fig 2A), this suggests that suppression of HMGB1 has a direct inhibitory effect on invasion of BC cells.

Knockdown of HMGB1 inhibited the expressions of VEGF-C through NF-kB. To further explore the relationship between HMGB1 and metastasis of BC, the effect of knockdown HMGB1 on VEGF-C was detected in 5637 BC cells. As a subunit of VEGF, VEGF-C is reported to be a factor that enhanced the permeability of the lymphatic system and connected with tumor

B
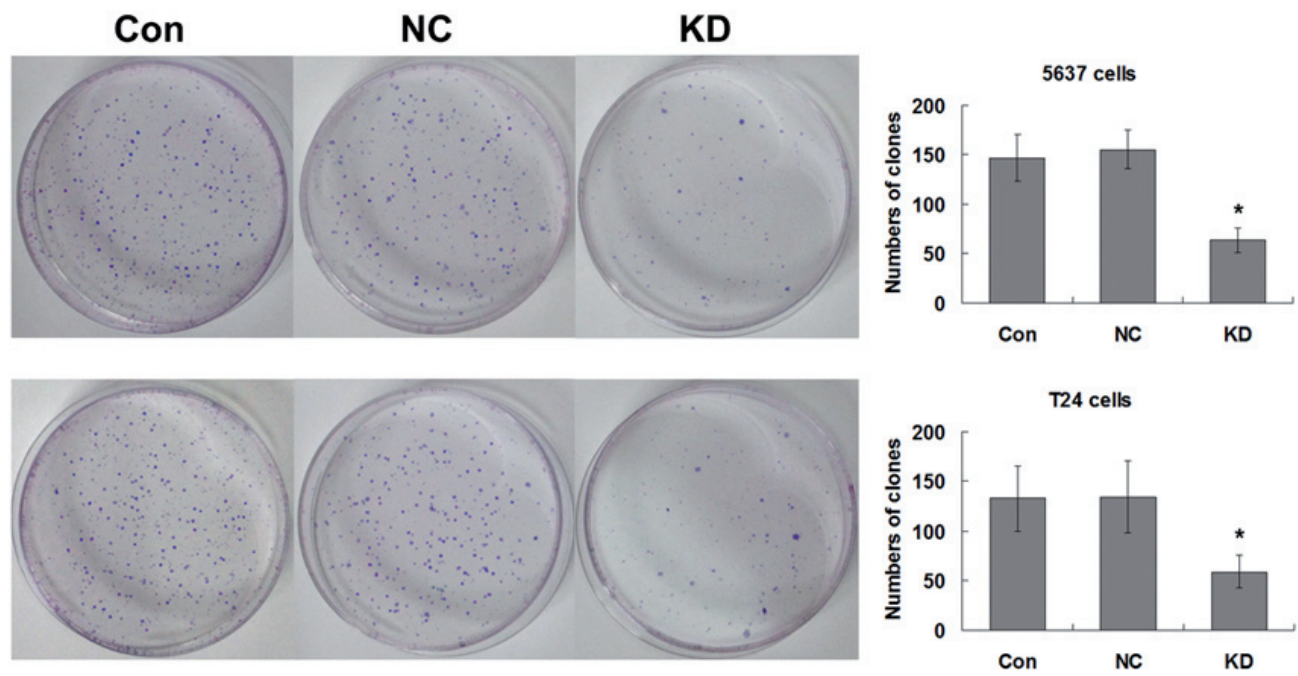

Figure 2. Knockdown of HMGB1 inhibited the growth of BC cells in vitro.

(A) HMGB1 down-regulation suppressed cell proliferation assessed by . MTT assay. (B) Knockdown of HMGB1 resulted in lower colony forming efficiency of BC cells. ${ }^{\star} p<0.05$, vs CON group. 
A

5637 cells

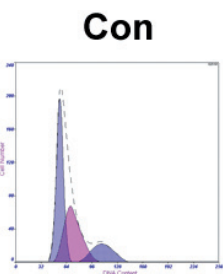

NC

KD
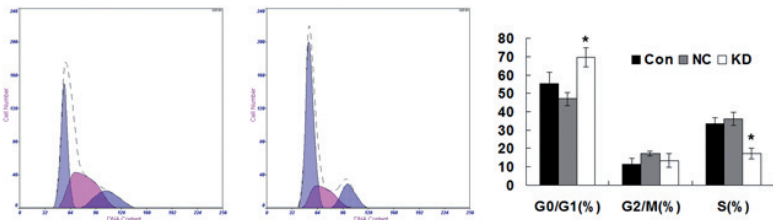

B
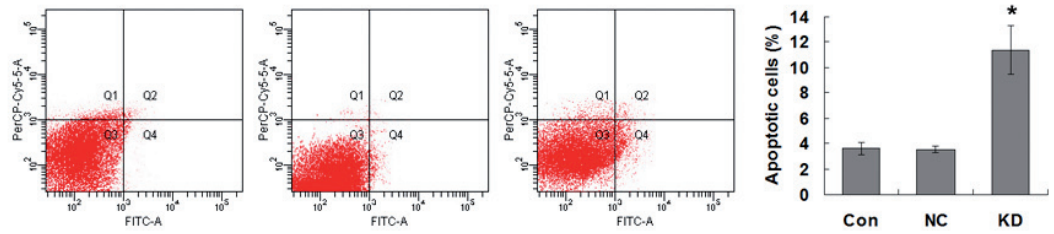

C
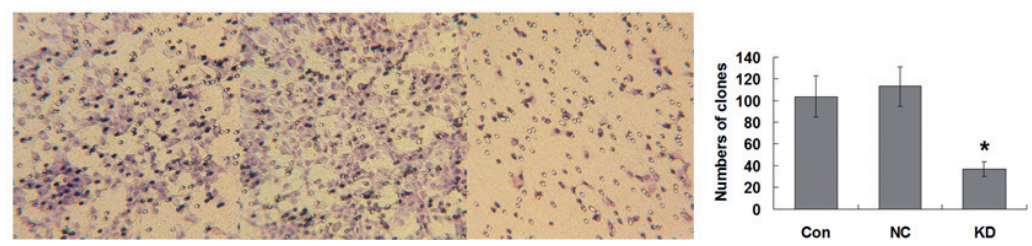

A

T24 cells
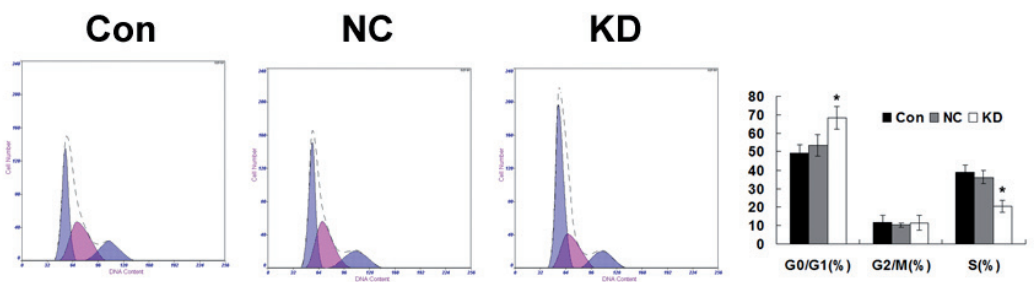

B
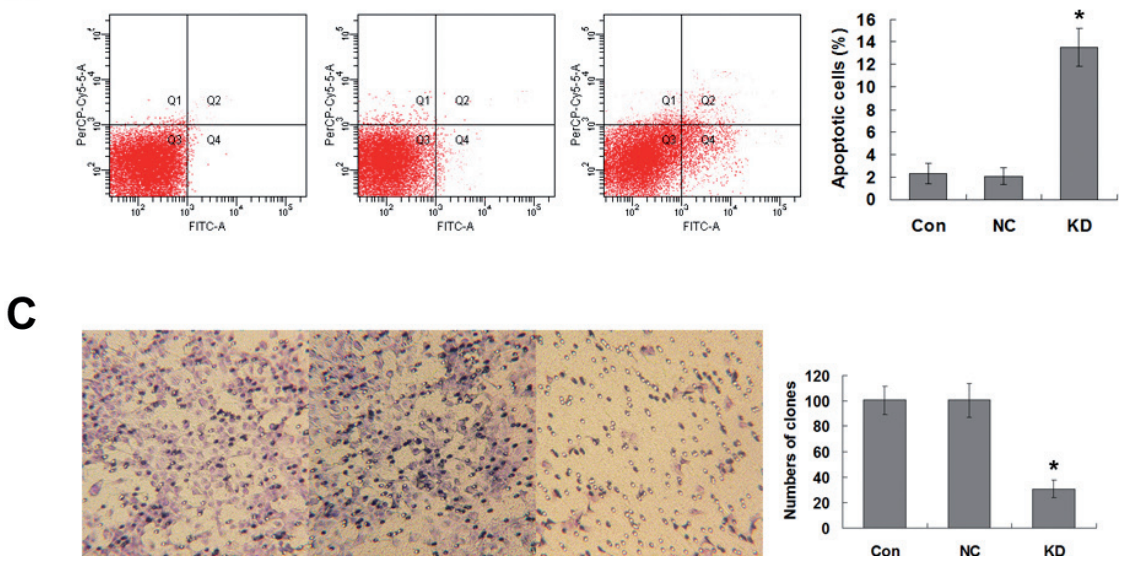

Figure 3. Knockdown of HMGB1 blocked cell cycles, increased cells apoptosis and inhibited invasive activity of BC cells in vitro.

(A) Cell cycles were analyzed using flow cytometry. Knockdown of HMGB1 resulted in an increase in the proportion of cells in the G0/G1 phase. (B) Cell apoptosis were determined by flow cytometry with PI/FITC-Annexin V staining. (C) Invasive cells are stained with hematoxylin and visualized by microscopy (original magnification $\times 200$ ). ${ }^{*} p<0.05$, vs CON group. 
invasion, lymph metastasis[20]. Our previous study showed that there was a significant correlation between VEGF and HMGB1 expression in BC tissue samples[18]. Moreover, increased evidences suggested that NF- $\mathrm{kB} / \mathrm{p} 65$ may play an important role linking HMGB1 and VEGF[20, 21].

The Western-blot assay indicated that the expressions of VEGF-C and NF- $\mathrm{kB} / \mathrm{p} 65$ were significantly decreased in the KD group compared to the CON groups ( $p<0.05$, Fig. $4 \mathrm{~A}$ and $B)$, suggesting lentivirus-mediated knockdown of HMGB1 could inhibit the expressions of VEGF-C and NF- $\mathrm{kB} / \mathrm{p} 65$. ELISA assay showed that the VEGF-C concentration was significantly decreased in the KD group $(211.58 \pm 8.16 \mathrm{pg} / \mathrm{ml})$ compared to the CON $(410.77 \pm 26.51 \mathrm{pg} / \mathrm{ml})$ groups $(p<0.05$, Fig. 4C). The NF- $\kappa B$ inhibitor PDTC could decrease the expression of VEGF-C $(187.94 \pm 39.01 \mathrm{pg} / \mathrm{ml})$, and HMGB1 as a NF- $\kappa B$ agonist could increase the expression of VEGF-C $(368.54 \pm 18.79 \mathrm{pg} / \mathrm{ml})$ significantly at the same time $(p<0.05$, Fig. 4C). It indicated that NF- $\kappa B$ activity was necessary for VEGF-C expression, and that HMGB1 may regulate VEGF-C expression via NF- $\kappa \mathrm{B}$ signaling pathway in $\mathrm{BC}$.

Injecting Lv-shHMGB1 inhibited tumorigenicity of BC cells in vivo. Tumors grew exponentially in all nude mice and a minimal difference was detected between mice within 10 days. Then mice were divided into three groups, the NS,
Lv-NC and Lv-HMGB1 groups, each group was given appropriate intervention. There were no significant differences on the state and weight of nude mice and no obvious abnormal changes in the tissues around tumor in $\mathrm{KD}$ group compared with CON group. Tumor volume of the NS group was about $840.40 \pm 146.43 \mathrm{~mm}^{3}$ and weighed about $0.90 \pm 0.27 \mathrm{~g}$ on day 30 , the data of the Lv-NC group was $775.87 \pm 202.49 \mathrm{~mm}^{3}$ and $0.81 \pm 0.25 \mathrm{~g}$. By contrast, mice in the Lv-HMGB1 group developed smaller tumors about $285.90 \pm 86.15 \mathrm{~mm}^{3}$ and $0.26 \pm 0.11 \mathrm{~g}$ $(p<0.05$, Fig. 5).

\section{Discussion}

The involvement of HMGB1 in cancer was complex. The intracellular and extracellular HMGB1 had been implicated in the response to cancer chemotherapy and also mediated of tumor formation, progression, angiogenesis, and metastasis [22]. HMGB1 might act as a sensor of DNA modification and facilitate p53 phosphorylation after exposure to genotoxic stress. It would become new component of the DNA damage signaling cascade and provide a novel promising target for chemotherapeutic intervention [23]. HMGB1 might be directly involved in cancer metastasis through promoting cell migration, modulating the adhesive properties of cells, and

A

B

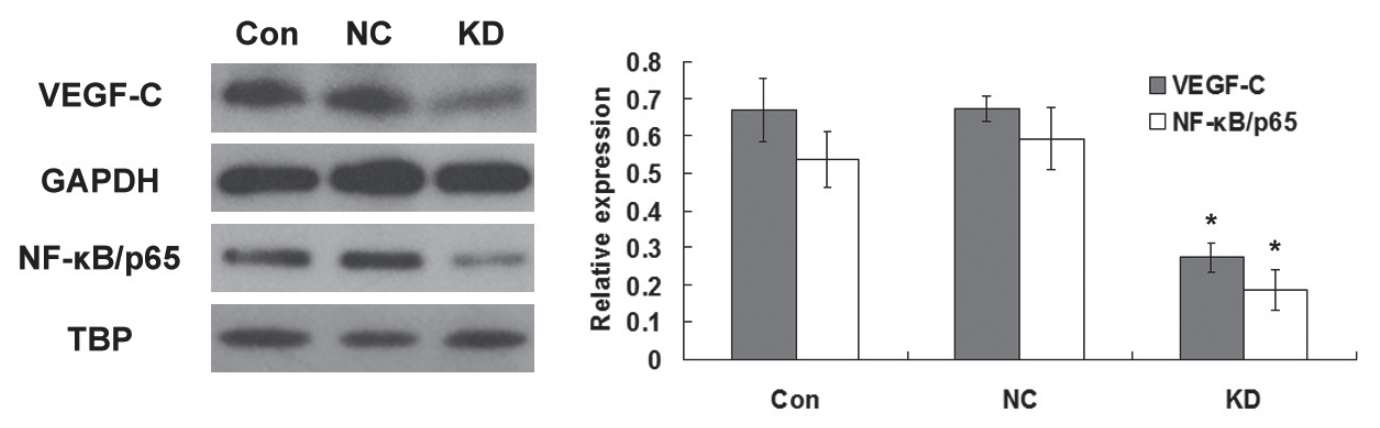

C

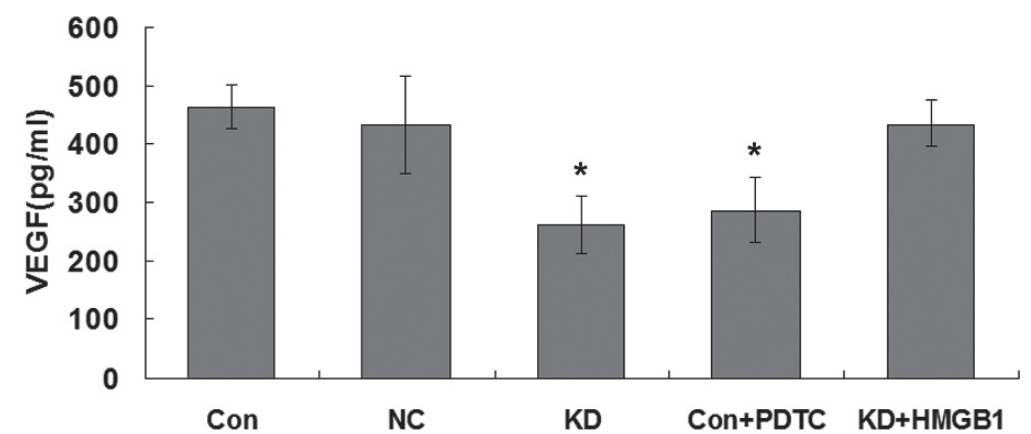

Figure 4. Lentivirus-mediated knockdown of HMGB1 inhibited the expressions of VEGF-C through NF-kB.

(A) and (B) The expressions of NF- $\mathrm{kB} / \mathrm{p} 65$ and VEGF-C were quantified by Western-blot assay. (C) VEGF-C concentration was detected by ELISA assay. ${ }^{*} p<0.05$, vs CON group. 
A

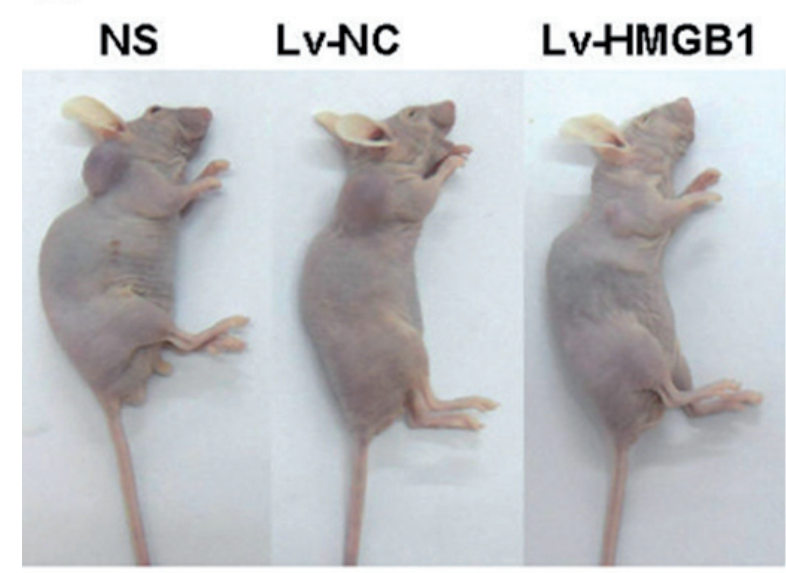

C

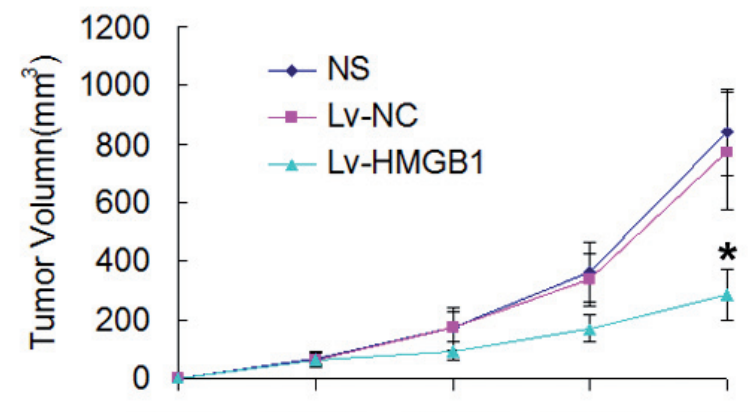

Day 0 Day10 Day15 Day22 Day3
B

\section{NS Lv-NC Lv-HMGB1}

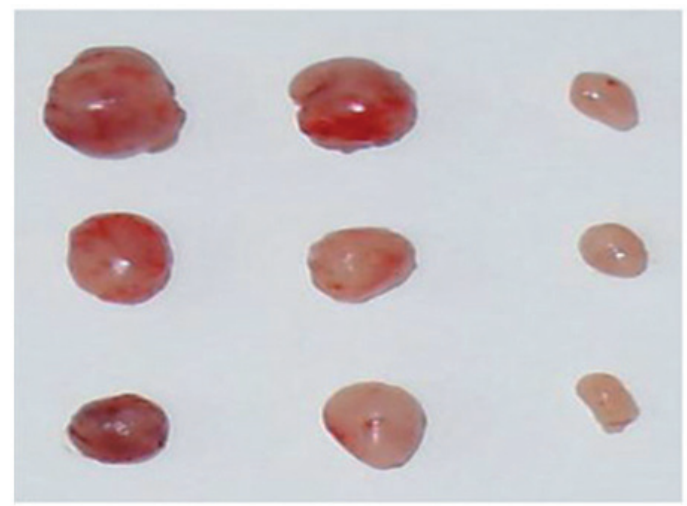

D

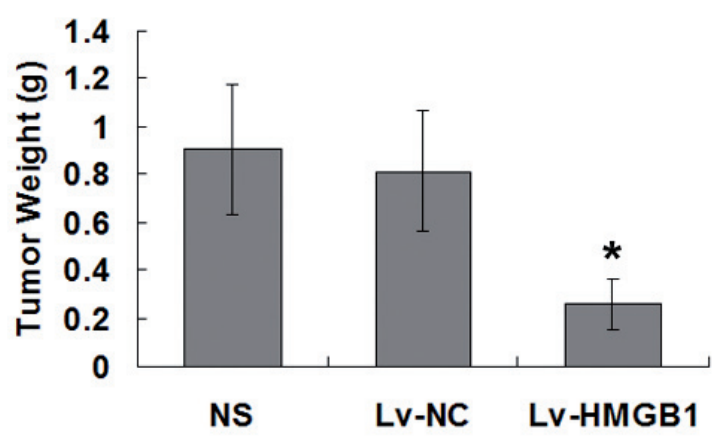

Figure 5. Injecting Lv-shHMGB1 inhibited tumorigenicity of BC cells in vivo

(A) and (B) Photographs of nude mice and tumors were taken 30 days after injection with BC cells. (C) Tumor volumes were recorded on day 10, 15, 22 and 30. (D) Mice were humanely killed and tumors were weighed on day $30 .{ }^{\star} p<0.05$, vs NS group.

modifying components of the extracellular matrix [9]. HMGB1 had been recognized as a latent proangiogenic factor in cancer progression and angiogenesis, it could stimulate endothelial cell proliferation and sprouting in vitro and neovascularization in vivo, and it might due to the production of the angiogenic factors such as VEGF [24]. In this study, lentivirus-mediated HMGB1 silencing strategy was used. Knockdown of HMGB1 induced strong suppression of $\mathrm{BC}$ cells growth, proliferation and invasive ability in vitro. In addition, downregulation of HMGB1 resulted in an increase in the proportion of BC cells in the G0/G1 phase and induced cells apoptosis. Injecting sh-HMGB1 lentivirus could decrease the 5637 BC cells proliferation and made the $5637 \mathrm{BC}$ cells nearly lost their tumorigenicity in nude mice models, indicating that inhibition of HMGB1 expression suppressed the tumorigenicity of $5637 \mathrm{BC}$ cells in vivo.

Extracellular HMGB1 could bind to specific membrane receptors, including the RAGE, TLR2 and TLR4[25], and activate key cell signaling pathway NF- $\mathrm{\kappa B} / \mathrm{p} 65$ and induced cancer cell growth, apoptosis, migration, invasion, and metastasis $[9,26]$. Abnormally activated NF- $\mathrm{kB} / \mathrm{p} 65$ could modulate the transcription and expression of VEGF, and was important in the development, metastasis and angiogenesis of cancers $[21,27]$. As a new subunit of VEGF, VEGF-C could bind to VEGFR2 and VEGFR3 to activate the MEK/ ERK, PI3K/Akt and MAPK pathways and involved in angiogenesis, lymphangiogenesis and the maintenance of adult lymphatic vasculature[20, 28]. VEGF-C was overexpressed in human lung cancer, gastric cancer, colon cancer and etc. Specific inhibition of the expression of the HMGB1 could suppress NF- $\mathrm{kB} / \mathrm{p} 65$ expression in hepatocellular carcinoma cells, which could reduce the expression of VEGF-C and inhibit tumor growth, proliferation, angiogenesis and invasion ability[29]. Fujioka found that inhibitied NF- $\mathrm{BB} / \mathrm{p} 65$ expression could decrease the resistance of pancreatic cancer to chemotherapy[30]. Our results indicated that downregulation of HMGB1 could inhibit the expression of NF- $\mathrm{\kappa B} / \mathrm{p} 65$ and VEGF-C in 5637 BC cells and HMGB1 may regulate VEGFC expression via the NF- $\kappa B$ signaling pathway. But HMGB1 signaling pathways were quite complex and many downstream 
molecules of HMGB1 were not yet entirely clear. It was worth further study in the future.

In conclusion, our work provided the evidence that HMGB1 has a potentially important role in the tumorigenicity of BC. Specific lentivirus-mediated knockdown of HMGB1 significantly impacted the proliferation, cell cycle, cells apoptosis and invasive ability of $\mathrm{BC}$ cells. Injecting lentivirus delivering shRNA against HMGB1 could decrease the $\mathrm{BC}$ cells proliferation and made the $\mathrm{BC}$ cells nearly lost their tumorigenicity in nude mice models. Furthermore, HMGB1 could regulate VEGF-C expression via the NF- $\mathrm{kB}$ signaling pathway possibly. This novel strategy may be a promising tool for BC therapy.

Acknowledgements: This work was supported by grant from National Natural Science Foundation of China (Project No. 81272835), Shanghai Science and Technology Commission and international cooperation projects (Project No. 11410708200).

\section{References}

1] SIEGEL R, NAISHADHAM D, and JEMAL A. Cancer statistics, 2013. CA CANCER J CLIN 2013; 63: 11-30. http://dx.doi. org/10.3322/caac. 21166

[2] CHEN W, ZHENG R, ZHANG S, ZHAO P, LI G, et al. Report of incidence and mortality in China cancer registries, 2009. Chinese journal of cancer research 2013; 25: 10-21.

[3] VIANELLO A, COSTANTINI E, DEL ZINGARO M, BINI V, HERR HW, et al. Repeated white light transurethral resection of the bladder in nonmuscle-invasive urothelial bladder cancers: systematic review and meta-analysis. J Endourol 2011; 25: 1703-12. http://dx.doi.org/10.1089/end.2011.0081

[4] KU JH AND LERNER SP. Strategies to prevent progression of high-risk bladder cancer at initial diagnosis. Curr Opin Urol 2012; 22: 405-14. http://dx.doi.org/10.1097/ MOU.0b013e328356adff

[5] VISHNU P, MATHEW J, AND TAN WW. Current therapeutic strategies for invasive and metastatic bladder cancer. OncoTargets and Therapy 2011; 4: 97-113.

[6] GAKIS G, SCHWENTNER C, TODENHOFER T, and STENZL A. Current status of molecular markers for prognostication and outcome in invasive bladder cancer. BJU Int 2012; 110: 233-7. http://dx.doi.org/10.1111/j.1464-410X.2011.10839.x

[7] NAGLOVA H AND BUCOVA M. HMGB1 and its physiological and pathological roles. Bratisl Lek Listy 2012; 113: 163-71.

[8] AGRESTI A AND BIANCHI ME. HMGB proteins and gene expression. Curr Opin Genet Dev 2003; 13: 170-8. http:// dx.doi.org/10.1016/S0959-437X(03)00023-6

[9] SIMS GP, ROWE DC, RIETDIJK ST, HERBST R, and COYLE AJ. HMGB1 and RAGE in inflammation and cancer. Annu Rev Immunol 2010; 28: 367-388. http://dx.doi.org/10.1146/ annurev.immunol.021908.132603

[10] WANG H, BLOOM O, ZHANG M, VISHNUBHAKAT JM, OMBRELLINO M, et al. HMG-1 as a late mediator of endotoxin lethality in mice. Science 1999; 285: 248-51. http:// dx.doi.org/10.1126/science.285.5425.248
[11] CHOW MT, MOLLER A, AND SMYTH MJ. Inflammation and immune surveillance in cancer. Semin Cancer Biol 2012; 22: 23-32. http://dx.doi.org/10.1016/ j.semcancer.2011.12.004

[12] KOSTOVA N, ZLATEVA S, UGRINOVA I, and PASHEVA E. The expression of HMGB1 protein and its receptor RAGE in human malignant tumors. Mol Cell Biochem 2010; 337: 251-258. http://dx.doi.org/10.1007/s11010-009-0305-0

[13] SHARMA A, RAY R, AND RAJESWARI MR. Overexpression of high mobility group (HMG) B1 and B2 proteins directly correlates with the progression of squamous cell carcinoma in skin. Cancer Invest 2008; 26: 843-51. http://dx.doi.org/ $\underline{10.1080 / 07357900801954210}$

[14] GNANASEKAR M, THIRUGNANAM S, and RAMASWAMY K. Short hairpin RNA (shRNA) constructs targeting high mobility group box-1 (HMGB1) expression leads to inhibition of prostate cancer cell survival and apoptosis. Int J Oncol 2009; 34: 425-431.

[15] YAO X, ZHAO G, YANG H, HONG X, BIE L, et al. Overexpression of high-mobility group box 1 correlates with tumor progression and poor prognosis in human colorectal carcinoma. J Cancer Res Clin Oncol 2010; 136: 677-84. http://dx.doi. org/10.1007/s00432-009-0706-1

[16] JIAO Y, WANG HC, and FAN SJ. Growth suppression and radiosensitivity increase by HMGB1 in breast cancer. Acta Pharmacol Sin 2007; 28: 1957-67. http://dx.doi.org/10.1111/ j.1745-7254.2007.00669.x

[17] YANG GL, ZHANG LH, BO JJ, HUO XJ, CHEN HG, et al. Increased expression of HMGB1 is associated with poor prognosis in human bladder cancer. J Surg Oncol 2012; 106: 57-61. http://dx.doi.org/10.1002/jso.23040

[18] WANG W, JIANG HW, ZHU HC, ZHANG H, GONG J, et al. Overexpression of high mobility group box 1 and 2 is associated with the progression and angiogenesis of human bladder carcinoma. Oncol Lett 2012;

[19] PFAFFL MW, HORGAN GW, and DEMPFLE L. Relative expression software tool (REST) for group-wise comparison and statistical analysis of relative expression results in realtime PCR. Nucleic Acids Res 2002; 30: e36. http://dx.doi. org/10.1093/nar/30.9.e36

[20] LOHELA M, BRY M, TAMMELA T, and ALITALO K. VEGFs and receptors involved in angiogenesis versus lymphangiogenesis. Curr Opin Cell Biol 2009; 21: 154-165. http://dx.doi. org/10.1016/j.ceb.2008.12.012

[21] DIDONATO JA, MERCURIO F, and KARIN M. NF-kappaB and the link between inflammation and cancer. Immunol Rev 2012; 246: 379-400. http://dx.doi.org/10.1111/j.1600065X.2012.01099.X

[22] TANG D, KANG R, ZEH HJ 3RD, and LOTZE MT. Highmobility group box 1, oxidative stress, and disease. Antioxid Redox Signal 2011; 14: 1315-1335. http://dx.doi.org/10.1089/ ars.2010.3356

[23] KRYNETSKAIA NF, PHADKE MS, JADHAV SH, AND KRYNETSKIY EY. Chromatin-associated proteins HMGB1/2 and PDIA3 trigger cellular response to chemotherapy-induced DNA damage. Mol Cancer Ther 2009; 8: 864-72. http://dx.doi. org/10.1158/1535-7163.MCT-08-0695 
[24] TANG D, KANG R, ZEH HJ 3RD, and LOTZE MT. High-mobility group box 1 and cancer. Biochim Biophys Acta 2010; 1799: 131-140. http://dx.doi.org/10.1016/ j.bbagrm.2009.11.014

[25] VAN BEIJNUM JR, BUURMAN WA, AND GRIFFIOEN AW. Convergence and amplification of toll-like receptor (TLR) and receptor for advanced glycation end products (RAGE) signaling pathways via high mobility group B1 (HMGB1). Angiogenesis 2008; 11: 91-9. http://dx.doi.org/10.1007/s10456-008-9093-5

[26] BALDWIN AS. Regulation of cell death and autophagy by IKK and NF-kappaB: critical mechanisms in immune function and cancer. Immunol Rev 2012; 246: 327-345. http://dx.doi. org/10.1111/j.1600-065X.2012.01095.X

[27] HALLAM S, ESCORCIO-CORREIA M, SOPER R, SCHULTHEISS A, and HAGEMANN T. Activated macrophages in the tumour microenvironment-dancing to the tune of TLR and NF-kappaB. J Pathol 2009; 219: 143-152. http://dx.doi.org/10.1002/path.2602

[28] ZHU C, QI X, CHEN Y, SUN B, DAI Y, et al. PI3K/Akt and MAPK/ERK1/2 signaling pathways are involved in IGF-1induced VEGF-C upregulation in breast cancer. J Cancer Res Clin Oncol 2011; 137: 1587-1594. http://dx.doi.org/10.1007/ s00432-011-1049-2

[29] JIANG W, WANG Z, LI X, LI J, HUANG Y, et al. Reduced high-mobility group box 1 expression induced by RNA interference inhibits the bioactivity of hepatocellular carcinoma cell line HCCLM3. Dig Dis Sci 2012; 57: 92-98. http://dx.doi. org $/ 10.1007 / \mathrm{s} 10620-011-1944-\mathrm{Z}$

[30] FUJIOKA S, SON K, ONDA S, SCHMIDT C, SCRABAS GM, et al. Desensitization of NFkappaB for overcoming chemoresistance of pancreatic cancer cells to TNF-alpha or paclitaxel. Anticancer Res 2012; 32: 4813-4821. 


\section{Supplementary Information}

\section{Targeting HMGB1 inhibits bladder cancer cells bioactivity by lentivirus- mediated RNA interference}

W. WANG ${ }^{1}$, H. ZHU ${ }^{3}$, H. ZHANG ${ }^{2}$, L. ZHANG 2 , Q. DING ${ }^{1,2}$, H. JIANG ${ }^{1,2, *}$

${ }^{1}$ Institute of Urology, Huashan Hospital, Fudan University; ${ }^{2}$ Department of Urology, Huashan Hospital, Fudan University; ${ }^{3}$ Department of ICU, Huashan Hospital, Fudan University

*Correspondence: drjianghaowen@126.com

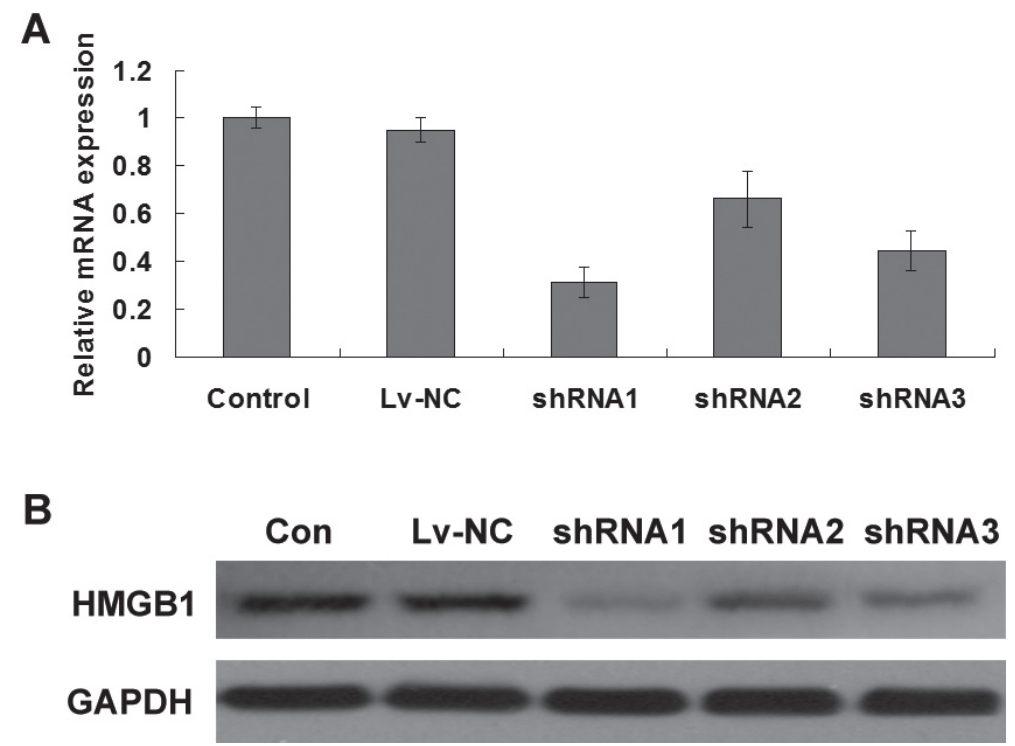

Figure S1. Interference efficiency of three potential shRNA sequences.

5637 BC cells were untreated or infected with Lv-shHMGB1 (shRNA1, 2 or 3) or Lv-NC. (A) Real-time PCR analysis of HMGB1 mRNA expression.(B) Immunoblot analysis of HMGB 1 protein expression.

Table S1 The designed shRNA sequences targeting human HMGB1 gene

\begin{tabular}{|c|c|c|}
\hline & siRNA sequences & shRNA sequences \\
\hline 1 & $5^{\prime}$-GAAGAAGATGAAGATGAAGAA-3' & 5'-GAAGAAGATGAAGATGAAGAATTCAAGAGATTCTTCATCTTCATCTTCTTCTTTTTTACGCGT-3` \\
\hline 2 & 5'-TGGGCAAAGGAGATCCTAAGA-3‘ & 5‘-TGGGCAAAGGAGATCCTAAGATTCAAGAGATCTTAGGATCTCCTTTGCCCATTTTTTACGCGT-3‘ \\
\hline 3 & 5'-CGGGAGGAGCATAAGAAGAAG-3‘ & 5'CGGGAGGAGCATAAGAAGAAGTTCAAGAGACTTCTTCTTATGCTCCTCCCGTTTTTTACGCGT-3“ \\
\hline
\end{tabular}

